\title{
GABA Enhances Transmission at an Excitatory Glutamatergic Synapse
}

\author{
Scott Gutovitz, John T. Birmingham, Jason A. Luther, David J. Simon, and Eve Marder \\ Volen Center and Biology Department, Brandeis University, Waltham, Massachusetts 02454-9110
}

GABA mediates both presynaptic and postsynaptic inhibition at many synapses. In contrast, we show that GABA enhances transmission at excitatory synapses between the lateral gastric and medial gastric motor neurons and the gastric mill $6 \mathrm{a}$ and 9 (gm6a, gm9) muscles and between the lateral pyloric motor neuron and pyloric 1 ( $p 1$ ) muscles in the stomach of the lobster Homarus americanus. Two-electrode current-clamp or voltageclamp techniques were used to record from muscle fibers. The innervating nerves were stimulated to evoke excitatory junctional potentials (EJPs) or excitatory junctional currents. Bath application of GABA first decreased the amplitude of evoked EJPs in gm6a and gm9 muscles, but not the p1 muscle, by activating a postjunctional conductance increase that was blocked by picrotoxin. After longer GABA applications (5-15 min), the amplitudes of evoked EJPs increased in all three muscles. This increase persisted in the presence of picrotoxin.
$\beta$-(Aminomethyl)-4-chlorobenzenepropanoic acid (baclofen) was an effective agonist for the GABA-evoked enhancement but did not increase the postjunctional conductance. Muscimol activated a rapid postsynaptic conductance but did not enhance the amplitude of the nerve-evoked EJPs. GABA had no effect on iontophoretic responses to glutamate and decreased the coefficient of variation of nerve-evoked EJPs. In the presence or absence of tetrodotoxin, GABA increased the frequency but not the amplitude of miniature endplate potentials. These data suggest that GABA acts presynaptically via a $\mathrm{GABA}_{\mathrm{B}}$-like receptor to increase the release of neurotransmitter.

Key words: Homarus americanus; crustaceans; lobster; neuromuscular junction; presynaptic modulation; stomatogastric nervous system; $G A B A_{B}$ receptors
Many synapses are influenced by substances that act directly on the presynaptic terminal to enhance or decrease the amount of neurotransmitter release. The mechanisms underlying this modulation of neurotransmitter release have been studied in numerous preparations and include modulation of voltage-dependent ion channels in presynaptic terminals, direct influences on secretion, and/or relatively direct modifications of presynaptic membrane potential (Delaney et al., 1991; Eliot et al., 1993; Hawkins et al., 1993; Wu and Saggau, 1997; MacDermott et al., 1999; Beaumont and Zucker, 2000).

GABA is among the substances that are well known to have presynaptic effects on neurotransmitter release in both vertebrate (Holz et al., 1989; Gage, 1992; Matthews et al., 1994; Isaacson and Hille, 1997; Lim et al., 2000) and invertebrate (Dudel and Kuffler, 1961; el Manira and Clarac, 1994; Fischer and Parnas, 1996; Rathmayer and Djokaj, 2000) preparations. In many cases, GABA is thought to inhibit transmitter release by direct actions on presynaptic $\mathrm{Ca}^{2+}$ channels, mediated by $\mathrm{GABA}_{\mathrm{B}}$ receptors (Dunlap and Fischbach, 1981).

GABA has both presynaptic and postsynaptic actions at many

\footnotetext{
Received March 26, 2001; revised May 21, 2001; accepted May 31, 2001.

This research was supported by National Institute of Neurological Disorder and Stroke Grants NS 17813 (E.M.) and NS 10564 (J.T.B.), by the Howard Hughes Medical Institute Summer Program for Undergraduates (S.G.), and by the W. M. Keck Foundation.

Correspondence should be addressed to Dr. Eve Marder, Volen Center, MS 013, Brandeis University, 415 South Street, Waltham, MA 02454-9110. E-mail: marder@brandeis.edu.

J. T. Birmingham's present address: Department of Physics, Santa Clara University, 500 El Camino Real, Santa Clara, CA 95053.

S. Gutovitz's present address: University of Kansas School of Medicine, 3901 Rainbow Boulevard, Kansas City, KS 66160.

Copyright (C) 2001 Society for Neuroscience $\quad 0270-6474 / 01 / 215935-09 \$ 15.00 / 0$
}

crustacean nerve terminals (Dudel and Kuffler, 1961). At the crayfish opener synapses, GABA released from the inhibitory nerve terminal opens postsynaptic $\mathrm{Cl}^{-}$channels. Additionally, GABA decreases the quantal content of the excitatory synapse (Dudel and Kuffler, 1961) onto the same fibers. Intracellular recordings from crayfish neuromuscular junctions showed that presynaptic inhibition is mediated by hyperpolarization of the terminals (Fuchs and Getting, 1980) and that GABA $_{\mathrm{B}}$ agonists decrease the release of transmitter from individual boutons at some crayfish neuromuscular junctions (Fischer and Parnas, 1996). Intracellular recordings made in presynaptic terminals at the stretcher muscle neuromuscular junction in spiny lobsters demonstrated a $\beta$-(aminomethyl)-4-chlorobenzenepropanoic acid (baclofen)-evoked membrane hyperpolarization that was blocked by application of pertussis toxin, suggesting the involvement of a $\mathrm{GABA}_{\mathrm{B}}$ receptor (Miwa et al., 1990).

Until recently, it was thought that the muscles of the crustacean stomach receive only excitatory innervation, although a few stomach muscles show a picrotoxin-sensitive increase in $\mathrm{Cl}^{-}$conductance in response to GABA (Albert et al., 1986). New anatomical evidence has suggested that there may be GABAergic innervation to some of the crustacean stomach muscles (Sharman et al., 2000; Swensen et al., 2000). This prompted us to reinvestigate the possible role of GABA at some of the neuromuscular junctions of the lobster Homarus americanus. Surprisingly, we found that GABA significantly enhances the amplitude of the excitatory synaptic potentials and currents recorded from fibers of some of the stomach muscles, by what appears to be a presynaptic mechanism mediated by $\mathrm{GABA}_{\mathrm{B}}$-like receptors. These data strongly suggest that GABA can act presynaptically to enhance transmitter release. 


\section{MATERIALS AND METHODS}

Animals and solutions. Lobsters, $H$. americanus, of both sexes were obtained from local seafood suppliers in Boston, MA, and kept in aerated aquaria at $10-12^{\circ} \mathrm{C}$. Physiological saline with the following composition (in $\mathrm{mm}$ ) was used: $479.12 \mathrm{NaCl}, 12.74 \mathrm{KCl}, 13.67 \mathrm{CaCl}_{2}, 10$ $\mathrm{MgSO}_{4}, 3.91 \mathrm{Na}_{2} \mathrm{SO}_{4}$, and 5 HEPES, pH 7.45 (Richards et al., 1999). GABA, L-glutamate, picrotoxin (PTX), and muscimol were purchased from Sigma (St. Louis, MO). Baclofen and 3-amino-2-(4-chlorophenyl)propylphosphonic acid (phaclofen) were purchased from Research Biochemicals (Natick, MA). Tetrodotoxin (TTX) was purchased from Alomone Laboratories (Jerusalem, Israel). The GABA $_{\mathrm{B}}$ antagonists (3-aminopropyl)(cyclohexylmethyl)phosphonic acid (CGP 46381), (3-aminopropyl)(diethoxymethyl)phosphinic acid (CGP 35348), and (3[[[(3,4-dichlorophenyl)methyl]amino]propyl]diethoxymethyl) phosphinic acid (CGP 52432) were purchased from Tocris Cookson, Inc. (Ballwin, MO).

The motor neuron somata of the stomatogastric ganglion (STG) make excitatory connections to the stomach muscles (Maynard and Dando, 1974). The gastric mill 9 (gm9) muscle is innervated solely by the medial gastric (MG) neuron via the lateral ventricular nerve (lvn). The gm6 muscle receives innervation from the lateral gastric (LG) neuron via the medial ventricular nerve (mvn) and from the MG neuron via the lvn. The pyloric 1 (p1) muscle is innervated solely by the lateral pyloric (LP) neuron via the lateral pyloric nerve. Nerve-muscle preparations were isolated from the animal and pinned flat in Sylgard-coated (Dow Corning, Midland, MI) $35 \mathrm{~mm}$ Petri dishes. The preparations were continuously superfused with saline $(\sim 10 \mathrm{ml} / \mathrm{min})$ by a gravity-fed system. Pharmacological agents were dissolved in saline immediately before use and then bath applied to the preparation by means of a switching port at the inflow of the superfusion system, which had a dead time of $\sim 1 \mathrm{~min}$. The bath volume was $\sim 3 \mathrm{ml}$ and, after the dead time, exchanged in $\sim 1$ min as determined by application of $1 \mathrm{~mm}$ L-glutamate. The saline was cooled to $10-12^{\circ} \mathrm{C}$ by means of a Peltier system.

Recordings. Intracellular recordings were made with microelectrodes filled with $0.6 \mathrm{M} \mathrm{K}_{2} \mathrm{SO}_{4}$ containing $20 \mathrm{mM} \mathrm{KCl}$ or with $3 \mathrm{M} \mathrm{KCl}$ in either two-electrode current-clamp or voltage-clamp mode using an Axoclamp-2A amplifier (Axon Instruments, Foster City, CA). Recording electrodes were 15-20 M $\Omega$; current-passing electrodes sometimes were of lower resistance. Motor nerves were stimulated extracellularly with a stainless steel bipolar pin electrode driven by an A-M Systems (Carlsborg, WA) pulse stimulator, model 2100. Glutamate was applied iontophoretically with hyperpolarizing current pulses (-200 nA; 200-500 msec) from a $60 \mathrm{M} \Omega$ electrode filled with $10^{-2} \mathrm{M}$ glutamate, $\mathrm{pH} 9$. Miniature excitatory junctional potentials (mEJPs) were recorded in 10 min stretches for each preparation in each condition. The mEJPs were counted by eye, and the amplitude was measured using the pClamp 8 software suite (Axon Instruments). Events were accepted if the amplitude exceeded peak-to-peak noise and had the fast rise time and slower decay characteristic of an excitatory junctional potential.

Data analysis. Statistical analyses were done with the SigmaStat software package (Jandel Scientific Software, San Rafael, CA). Data are reported as means \pm SEs.

\section{RESULTS}

\section{The gm6a EJP increases in the presence of GABA}

Albert et al. (1986) showed that bath application of $5 \times 10^{-4} \mathrm{M}$ GABA decreased the input resistance of gm6 muscle fibers in $H$. americanus. The decrease was blocked by PTX, indicating that a $\mathrm{GABA}_{\mathrm{A}}$-like receptor was responsible for the resistance change. Figure $1 A$ shows a simultaneous measurement of muscle input resistance and nerve-evoked EJPs in the gm6a muscle. A hyperpolarizing current pulse $(-50 \mathrm{nA} ; 2 \mathrm{sec})$ was injected into the muscle fiber every $10 \mathrm{sec}$, and the change in membrane potential was recorded. Between each current pulse, the lvn was stimulated for $2 \mathrm{sec}$ at $5 \mathrm{~Hz}$ to evoke EJPs. In Figure $1 A$ the dark line is the muscle fiber membrane potential, the negative deflections are hyperpolarizations resulting from the current injections, and the positive deflections are EJP trains compressed on this time base. At time 0 , the inflow stopcock was turned, starting flow of $10^{-4} \mathrm{M}$ GABA into the bath system. Approximately 1 min after bath application was started, the muscle resistance began to decrease, accompanied by a small depolarization $(\sim 2 \mathrm{mV})$ of the resting potential. The conductance peaked 2 min into the GABA application, and the effect partially desensitized during the next 13 min. Full $I-V$ curves (data not shown) in control saline and after 2 min in $10^{-4} \mathrm{M}$ GABA confirmed that the input resistance clearly decreased in GABA.

The expanded traces at the top of Figure $1 A$ show EJP trains at time 0 and after 2 and $15 \mathrm{~min}$ in GABA. Two points should be noted. First, within each train there was substantial quantal variability in the EJP amplitude, although facilitation during the train tended to increase the amplitude of the EJPs. Second, the EJP amplitudes were larger after $15 \mathrm{~min}$ in GABA than they were in control saline. This was particularly pronounced for the first EJP in the train, and so we focused further experiments on unitary EJPs evoked by single stimulations of the nerve.

Figure $1 B$ shows nerve-evoked unitary gm6a EJPs measured in control saline, after 2 min of bath application of $10^{-4} \mathrm{M}$ GABA, and after $15 \mathrm{~min}$ of $10^{-4} \mathrm{M}$ GABA. The EJP amplitude after 2 min was comparable with that of the control but decayed more quickly than did that of the control, consistent with a decreased muscle resistance. The EJP amplitude after 15 min was larger than that in control saline. Thirty minutes after switching back to control saline, the EJP amplitude returned to its initial value (data not shown). Figure $1 C$ summarizes the average peak gm6a EJP amplitude across preparations $(n=9)$ in control saline, 2 min after beginning bath application of $10^{-4} \mathrm{M}$ GABA, and after $15 \mathrm{~min}$ in $10^{-4} \mathrm{M}$ GABA. For each condition we averaged the response of five EJPs made at $10 \mathrm{sec}$ intervals. The increase after 15 min was significant (one-way ANOVA, $p<0.001$ ).

Figure $1 D$ summarizes the dependence of the EJP amplitude on GABA concentration ( $n=4$ experiments). During each experiment the concentration of GABA was varied from $10^{-6}$ to $10^{-3} \mathrm{M}$. A concentration of GABA was applied for $15 \mathrm{~min}$, the measurement was made, and then the preparation was rinsed in control saline for 30-40 $\mathrm{min}$ before the next application of GABA. The change in EJP amplitude with respect to control was significant in $10^{-4}$ and $10^{-3}$ M GABA (one-way ANOVA, $p<$ 0.01 and $p<0.001$, respectively).

\section{Muscimol mimics the GABA actions on muscle fiber input impedance}

Previous work reported by Albert et al. (1986) showed that picrotoxin blocked the postsynaptic conductance change evoked by GABA, and we replicated this effect (data not shown). This suggested that a $\mathrm{GABA}_{\mathrm{A}}$-like receptor could mediate the postjunctional effect of GABA. To characterize the pharmacology of this receptor further, we bath applied $10^{-4} \mathrm{M}$ muscimol and measured gm6a muscle fiber input impedance and EJP amplitude. In data from seven preparations, muscimol evoked a modest increase in conductance from $27.5 \pm 9.2$ to $30.9 \pm 10.0 \mu \mathrm{S}$ (paired $t$ test, $p<0.03$ ), but no significant change in EJP amplitude was seen (data not shown).

\section{PTX does not block the GABA enhancement of EJP amplitude}

To determine whether the increase in EJP amplitude seen in GABA was PTX-sensitive, we repeated the experiments summarized in Figure $1 C$ in the presence of $10^{-4} \mathrm{M} \mathrm{GABA}$ and $10^{-5} \mathrm{M}$ PTX. The average EJP amplitude $(n=5)$ was $1.56 \pm 0.33 \mathrm{mV}$ in PTX and was $2.30 \pm 0.29 \mathrm{mV}$ after $15 \mathrm{~min}$ in GABA and PTX. The difference in the amplitude was significant (paired $t$ test, $p<0.05$ ). 
A

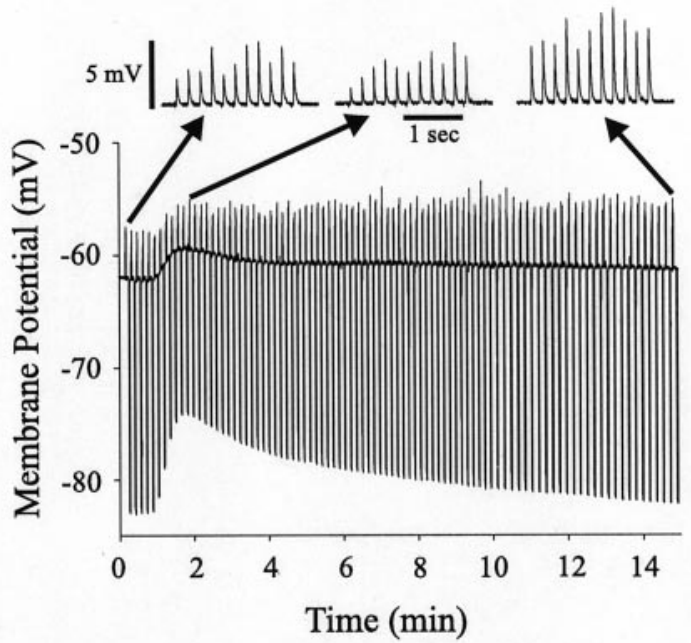

B

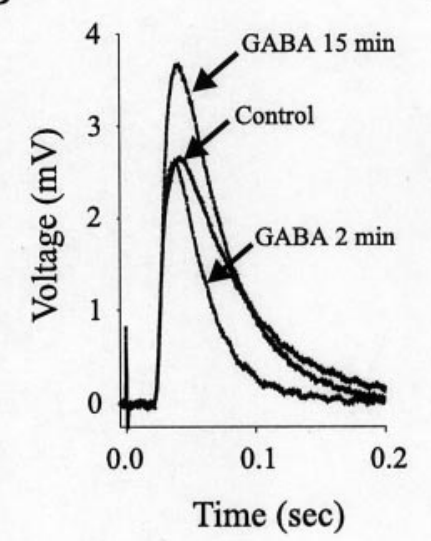

D

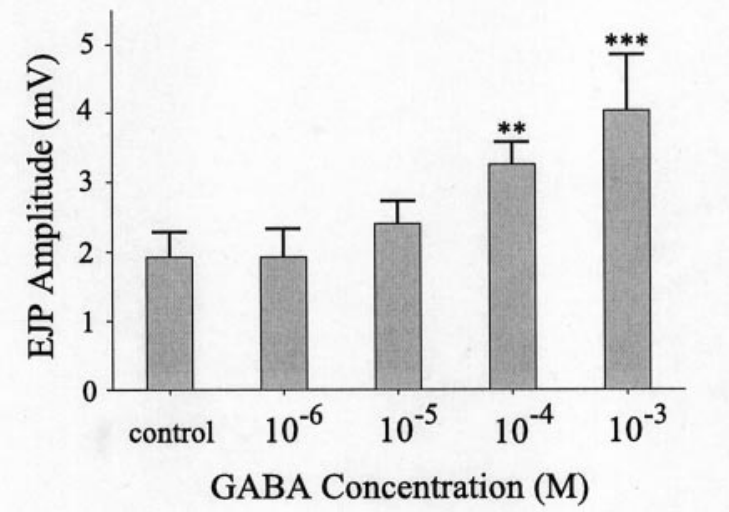

Figure 1. The effect of GABA on membrane conductance and EJP amplitude. $A$, Membrane potential in lobster gm6a muscle fiber in response to alternating hyperpolarizing current injections $(-50 \mathrm{nA} ; 2 \mathrm{sec}$ duration; $10 \mathrm{sec}$ period) and electrical stimulation of the lvn $(5 \mathrm{~Hz} ; 2 \mathrm{sec}$ duration; 10 sec period). At time 0 , the inflow stopcock was turned, starting flow of $10^{-4}$ M GABA into the bath. The dark line is the membrane potential. The traces above the main plot show trains of EJPs at times of 0,2 , and $15 \mathrm{~min}$. $B$, Nerve-evoked EJP in a gm6a muscle fiber in control saline (Control), after $2 \mathrm{~min}$ in $10^{-4} \mathrm{M}$ GABA, and after $15 \mathrm{~min}$ in $10^{-4} \mathrm{M}$ GABA. $C$, A bar graph plot of average peak gm6a EJP amplitude $(n=9)$ in control saline, after 2 min in $10^{-4} \mathrm{M}$ GABA, and after $15 \mathrm{~min}$ in GABA. The increase in amplitude after 15 min was significant (one-way ANOVA, ${ }^{* *} p<0.001$ ). $D$, A bar graph plot showing the dependence of EJP amplitude (15 min after beginning bath application) on GABA concentration $(n=4)$. The increases in EJP amplitude were significant in $10^{-4}$ and $10^{-3} \mathrm{M}$ GABA (one-way ANOVA, ${ }^{* *} p<0.01 ; * * p<0.001$ ).
A

B
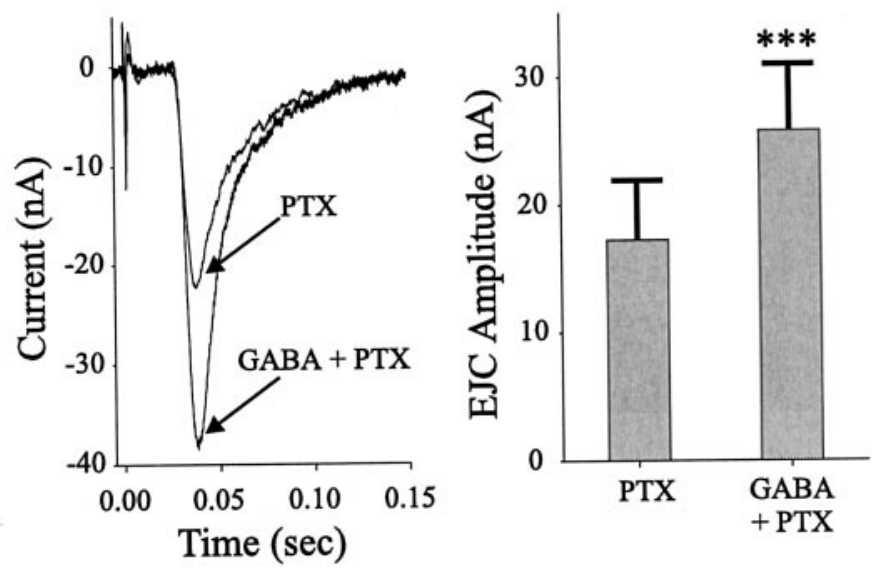

Figure 2. GABA enhances EJC amplitude. $A$, Nerve-evoked EJC in a gm6a muscle fiber in control saline with $10^{-5} \mathrm{M}$ PTX and after $15 \mathrm{~min}$ of bath application of $10^{-4} \mathrm{M}$ GABA and $10^{-5} \mathrm{M}$ PTX. $B$, A bar graph plot showing that the average peak gm6a EJC amplitude increases after 15 min of bath application of $10^{-4} \mathrm{M}$ GABA and $10^{-5} \mathrm{M}$ PTX compared with control saline with $10^{-5} \mathrm{M} \operatorname{PTX}(n=5$; paired $t$ test, $* * * p<0.001)$.

\section{The gm6a excitatory junctional current increases in the presence of GABA}

To determine whether the increase in EJP amplitude resulted from an increase in postsynaptic current, we voltage clamped fibers to $-70 \mathrm{mV}$ and measured MG-evoked excitatory junctional currents (EJCs) in gm6a in the absence and presence of GABA. All measurements were done in $10^{-5}$ м PTX. Figure $2 A$ shows examples of nerve-evoked EJCs measured in a gm6a muscle fiber in PTX and after $15 \mathrm{~min}$ of bath application of $10^{-4} \mathrm{M}$ GABA and PTX. Each trace is an average of five EJCs taken at $10 \mathrm{sec}$ intervals. Figure $2 B$ shows the average peak EJC amplitude in PTX and after 15 min in GABA and PTX $(n=5)$. The increase in amplitude was significant (paired $t$ test, $p<0.001$ ).

\section{The presynaptic and postsynaptic effects of GABA have different time courses}

The presence of the postsynaptic conductance change elicited by GABA confounded the estimation of the time course of the EJP enhancement. To gain a better estimate of the time course of the enhancement of the EJPs by GABA under our experimental conditions, we first measured the change in conductance evoked by bath application of glutamate, the neurotransmitter at this synapse (Lingle, 1980), or muscimol, which mimics only the postsynaptic action of GABA. Under our flow conditions, in the gm6a muscle we found that the peak changes in conductance evoked by bath application of $10^{-3} \mathrm{M}$ glutamate and $10^{-4} \mathrm{M}$ muscimol occurred in $<90 \mathrm{sec}$ after the agonists entered the bath (i.e., after the 1 min bath system dead time) (Fig. 3). However, the peak changes in EJP amplitude evoked by GABA in the presence of PTX did not occur until $\sim 3-4$ min after GABA and PTX entered the bath (Fig. 3). The glutamate and muscimol time courses were statistically indistinguishable, but the time to peak of the GABA-evoked EJP enhancement was statistically longer (one-way ANOVA, $p<0.05$ ).

GABA enhances the p1 EJP amplitude without eliciting a postsynaptic conductance change

Unlike in the gm6a and gm9 muscles, bath application of $10^{-4} \mathrm{M}$ GABA increased the nerve-evoked EJP in the p1 muscle but did 


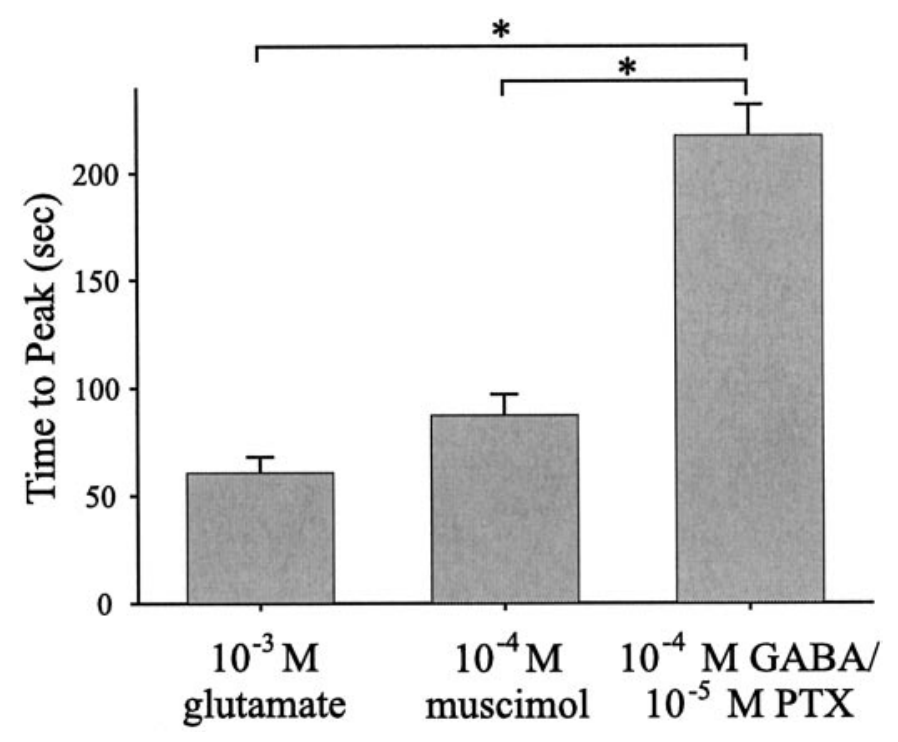

Figure 3. GABA enhancement of EJP amplitude in the gm6a muscle is slower than the postjunctional effects of glutamate or muscimol. The average time-to-peak response to bath application of $10^{-3} \mathrm{M}$ L-glutamate $(60.8 \pm 7.2 \mathrm{sec} ; n=8)$ or $10^{-4} \mathrm{M}$ muscimol $(87.3 \pm 9.6 \mathrm{sec} ; n=7)$ was faster than the time-to-peak EJP enhancement caused by $10^{-4} \mathrm{M}$ GABA and $10^{-5}$ M PTX (217 $\pm 14.36 \mathrm{sec} ; n=4$; one-way ANOVA, $\left.{ }^{*} p<0.05\right)$. However, the time-to-peak response for glutamate or muscimol did not statistically differ from that of the other.

not cause a postjunctional conductance change. Figure $4 A$ shows a current-clamp trace recorded in a p1 fiber. Downward deflections represent hyperpolarizing current injections $(-50 \mathrm{nA} ; 5$ sec), and upward deflections represent nerve-evoked EJPs (stimulated at $1 \mathrm{~Hz}$ for $15 \mathrm{sec}$ ). This preparation responded to GABA application (inflow stopcock turned at time 0 ) with no significant change in postsynaptic conductance but with an increase in the EJP amplitude after $\sim 15 \mathrm{~min}(6.95 \pm 0.10 \mathrm{mV}$ in control vs $7.27 \pm 0.11 \mathrm{mV}$ in GABA; average of 15 traces; Student's $t$ test, $p<0.05$ ). In contrast to observations in the gm6a muscle, GABA application resulted in no significant postsynaptic conductance increase $\left(3.10 \pm 0.48 \mu \mathrm{S}\right.$ in control vs $3.12 \pm 0.51 \mu \mathrm{S}$ in $10^{-4} \mathrm{M}$ GABA, measured 2 min after turning inflow stopcock; $n=4$; Fig. $4 B$ ). Figure $4 C$ shows that EJP amplitude increased after long GABA applications $(3.76 \pm 0.81 \mathrm{mV}$ in control vs $4.49 \pm 0.81 \mathrm{mV}$ in $10^{-4}$ M GABA; $n=6$; Wilcoxon signed rank test, $p<0.05$ ). This enhancement peaked $\sim 12$ min after GABA entered the bath. Nerve-evoked EJPs recorded from a single preparation (average of 30 traces) are shown in the inset.

\section{The EJP amplitude increases in the presence of the $\mathrm{GABA}_{\mathrm{B}}$ agonist baclofen}

The relatively slow time course of the GABA effect on EJP enhancement suggested that this action of GABA could be mediated by a $\mathrm{GABA}_{\mathrm{B}}$-like receptor. In a recent study of GABA responses in the neurons in the STG of the crab Cancer borealis, it was observed that the $\mathrm{GABA}_{\mathrm{B}}$ agonist baclofen affected membrane conductances (Swensen et al., 2000). We applied $10^{-4} \mathrm{M}$ baclofen to see whether it mimicked the slow GABA effect on the MG-gm6a EJP amplitude. Bath application of baclofen had no significant postsynaptic effect on membrane conductance $(n=4$; $22.3 \pm 0.02 \mu \mathrm{S}$ in control saline vs $22.6 \pm 0.02 \mu \mathrm{S}$ in baclofen; paired $t$ test). Membrane conductance measurements in baclofen were made at a time when application of L-glutamate or GABA would be expected to generate a peak postsynaptic response ( 2

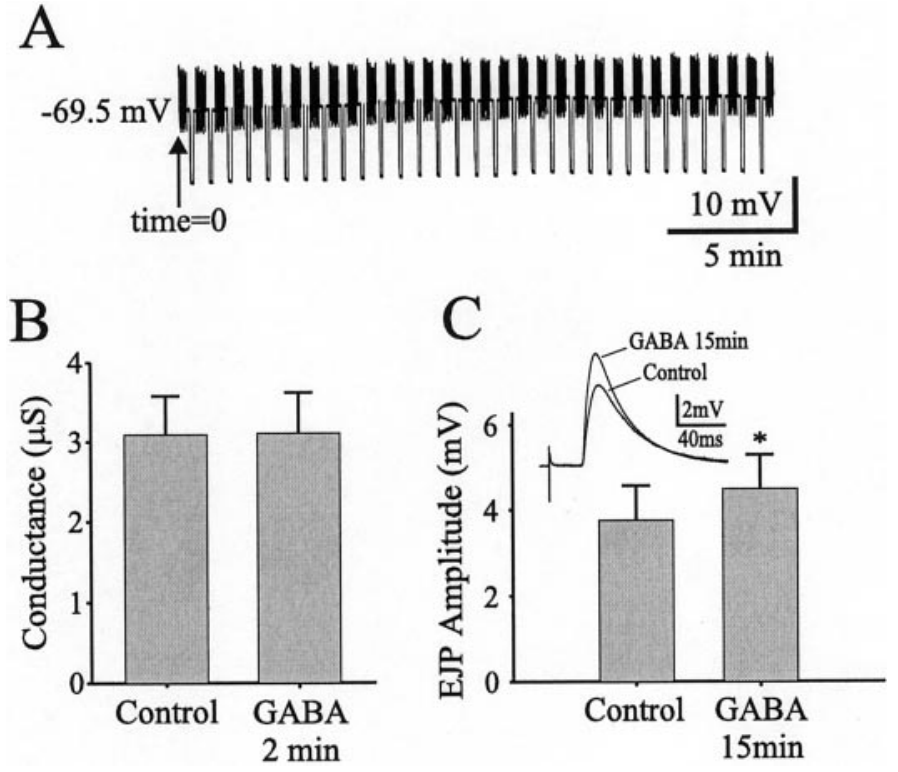

Figure 4. GABA increases EJP amplitude in p1 muscle fibers but causes no postsynaptic effect. $A$, A current-clamp recording made in a p1 fiber. Downward deflections represent current injections ( $-50 \mathrm{nA} ; 5 \mathrm{sec})$, and upward deflections are EJPs stimulated at $1 \mathrm{~Hz}$ for $15 \mathrm{sec}$ (compressed on this time base). The postsynaptic conductance did not significantly change throughout GABA application $(3.8 \pm 0.02 \mu \mathrm{S}$ in control, $3.7 \pm 0.02 \mu \mathrm{S}$ measured at $2 \mathrm{~min}$, and $3.7 \pm 0.04 \mu \mathrm{S}$ at $10 \mathrm{~min}$ ), but EJP amplitude became larger $(6.95 \pm 0.10 \mathrm{mV}$ in control vs $7.27 \pm 0.11 \mathrm{mV}$ after $15 \mathrm{~min}$ in GABA; average of 15 traces; Student's $t$ test, * $p<0.05)$. B, A bar graph plot of p1 muscle fiber conductance measured in control and 2 min after the start of the flow of GABA showing that there was no significant postsynaptic conductance increase $(3.10 \pm 0.48 \mu \mathrm{S}$ in control vs $3.12 \pm$ $0.51 \mu \mathrm{S}$ in $\left.10^{-4} \mathrm{M} \mathrm{GABA} ; n=4\right)$. $C$, A bar graph showing that GABA increased EJP amplitude from $3.76 \pm 0.81 \mathrm{mV}$ in control to $4.49 \pm 0.81$ $\mathrm{mV}$ after a $15 \mathrm{~min}$ application $\left(n=6\right.$; Wilcoxon signed rank test, ${ }^{*} p<$ $0.05)$. Inset, Averages of 30 EJPs recorded from a single preparation in control and after a $15 \mathrm{~min}$ application of $10^{-4} \mathrm{M}$ GABA, which increased the peak amplitude by $\sim 40 \%$.

min after inflow stopcock was turned). Figure 5 shows a PTXinsensitive increase in EJP amplitude. Traces were recorded from a gm6a fiber $(n=5 ; 2.06 \pm 0.42 \mathrm{mV}$ in PTX vs $2.92 \pm 0.18 \mathrm{mV}$ after $15 \mathrm{~min}$ in baclofen and PTX). The difference in the amplitude was significant (paired $t$ test, $p<0.05$ ).

Baclofen $\left(10^{-4} \mathrm{M}\right)$ also caused an increase in EJP amplitude in six of seven LP-p1 nerve-muscle preparations $(5.06 \pm 0.54 \mathrm{mV}$ in control saline vs $5.60 \pm 0.57 \mathrm{mV}$ in baclofen; paired $t$ test, $p<$ 0.05 ) but had no apparent effect on postsynaptic conductance (data not shown).

Previous work on crustacean GABA responses showed that although agonists of different classes were often effective, antagonists to vertebrate GABA receptors are often ineffective (Swensen et al., 2000). We tried a number of different GABA antagonists including phaclofen (Kerr et al., 1987), CGP 46381 (Olpe et al., 1993), CGP 35348 (Olpe et al., 1990, 1993), and CGP 52432 (Lanza et al., 1993). None of these blocked the EJP enhancement evoked by GABA (phaclofen, $10^{-4}$ M; $n=5$; CGP $46381,10^{-5}$ to $2 \times 10^{-4} \mathrm{M} ; n=4$; CGP $35348,7 \times 10^{-5} \mathrm{M} ; n=1$; CGP 54626, $1.7 \times 10^{-5} \mathrm{M} ; n=2$ ).

\section{The response to iontophoretically applied glutamate does not increase in GABA}

The LG, MG, and LP neurons release glutamate as their neurotransmitter (Lingle, 1980). To ask whether GABA application 

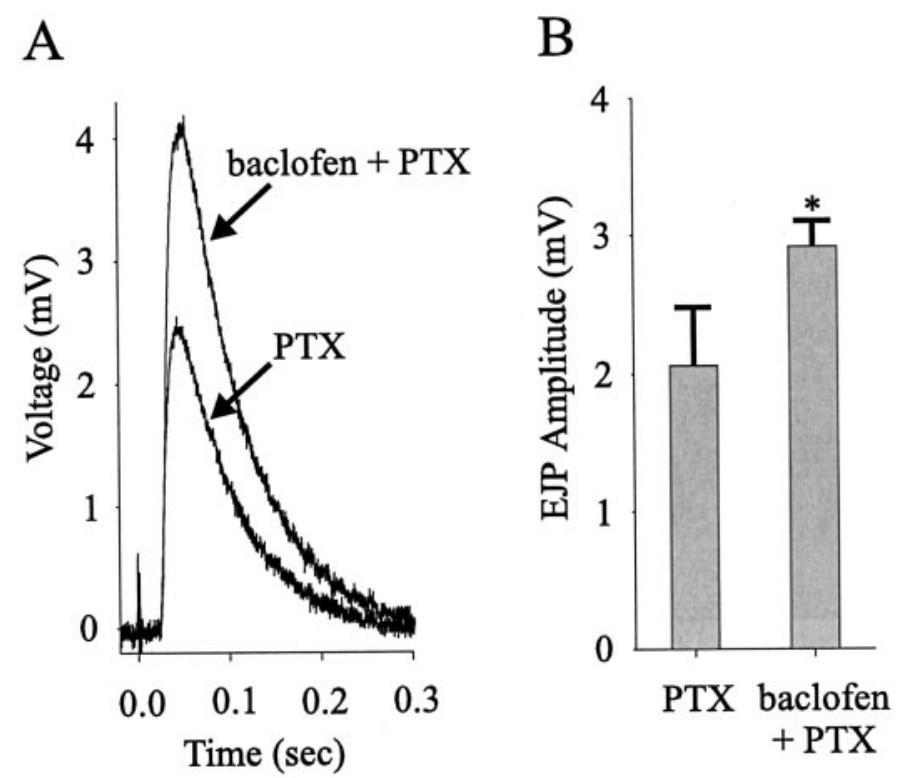

Figure 5. Baclofen mimics the effect of GABA on the EJP amplitude. $A$, The nerve-evoked EJP recorded in a gm6a muscle fiber was increased by $\sim 40 \%$ in $10^{-4} \mathrm{M}$ baclofen compared with control. This increase was not blocked by $10^{-5}$ M PTX. $B$, A bar graph plot shows that the average nerve-evoked EJP was increased in five preparations after a 15 min bath application of $10^{-4} \mathrm{M}$ baclofen and $10^{-5} \mathrm{M}$ PTX (paired $t$ test, ${ }^{*} p<0.05$ ).

A
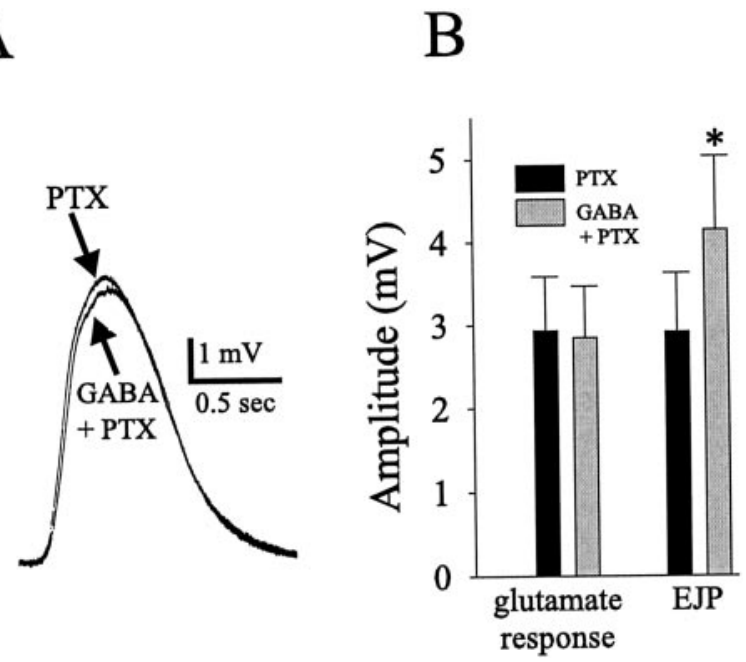

Figure 6. GABA has no effect on the response to iontophoretically applied glutamate. $A$, The gm6a response to iontophoretic application of $10^{-2} \mathrm{M}$ glutamate was not changed after a $15 \mathrm{~min}$ application of $10^{-4} \mathrm{M}$ GABA. PTX $\left(10^{-5} \mathrm{M}\right)$ was present in both measurements. Each trace is an average of five glutamate responses taken $20 \mathrm{sec}$ apart. $B$, A bar graph plot is shown of average EJP amplitude and the response to iontophoretically applied glutamate in $10^{-5} \mathrm{M}$ PTX (black bars) and after $15 \mathrm{~min}$ in $10^{-4} \mathrm{M}$ GABA and PTX ( gray bars) $(n=6)$. The iontophoretic response after a 15 min application of GABA was not significantly different from the control, although the nerve-evoked EJP amplitude was significantly increased (paired $t$ test, ${ }^{*} p<0.05$ ).

altered the postjunctional actions of glutamate, we measured the postsynaptic potential obtained in response to iontophoretically applied glutamate in the absence and presence of GABA. The measurements were done in the presence of $10^{-5}$ M PTX. Figure $6 A$ shows a typical response to iontophoretically applied glutamate in PTX and after $15 \mathrm{~min}$ of bath application of $10^{-4} \mathrm{M}$
A
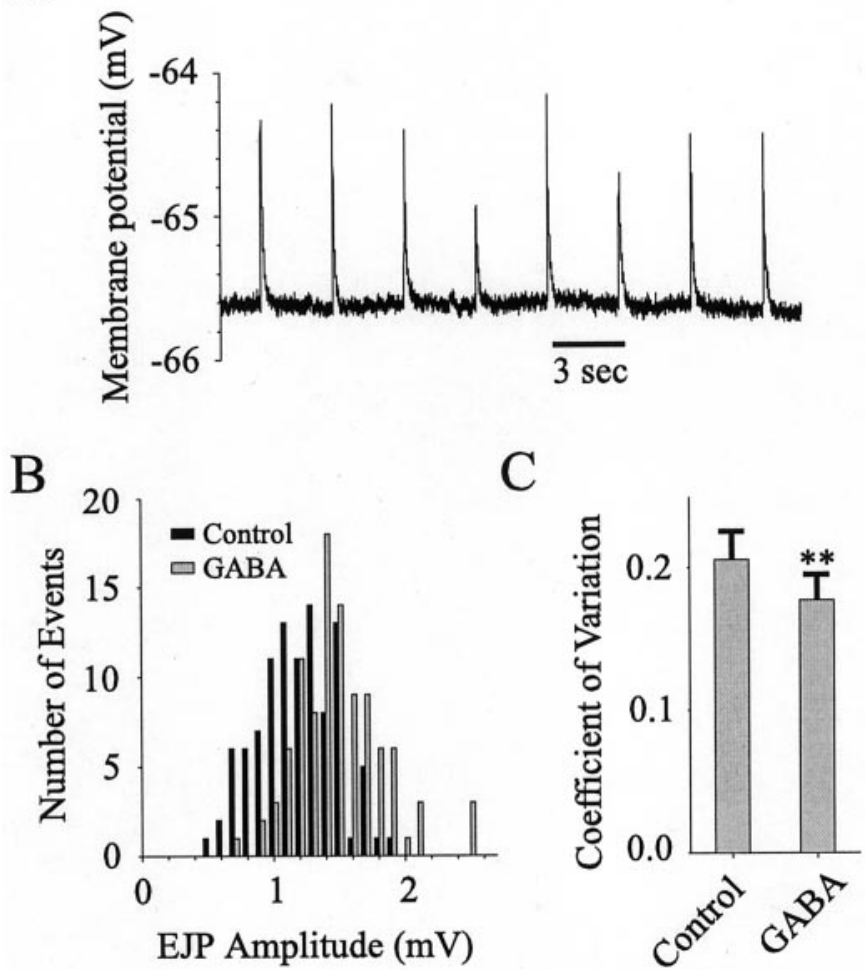

Figure 7. GABA decreases the coefficient of variation of nerve-evoked EJPs. $A$, Nerve-evoked MG EJPs in a gm6a muscle fiber in control saline (3 sec interstimulus interval) showing variation in EJP amplitude. $B$, Histogram plots of EJP amplitude recorded in a single preparation in control saline (black bars) and after $15 \mathrm{~min}$ in $10^{-4} \mathrm{M}$ GABA ( gray bars). For each condition, 100 EJPs were measured. The mean amplitude and $\mathrm{CV}$ were $1.13 \mathrm{mV}$ and 0.26 for control and $1.45 \mathrm{mV}$ and 0.23 in GABA, respectively. $C$, A bar graph plot showing that the average $\mathrm{CV}$ significantly decreased after 15 min in GABA compared with control $(n=4$; paired $t$ test, $\left.{ }^{* *} p<0.01\right)$.

GABA and PTX. Each trace is an average of five pulses taken 20 sec apart. Very little difference is seen in the two conditions. To check that GABA increased EJP amplitude in these preparations, a nerve-evoked EJP was stimulated between each iontophoretic pulse and measured using the same electrode. The effects of GABA on the average peak response to applied glutamate and on the average EJP amplitude are shown in Figure $6 B(n=6)$. The glutamate response was not significantly changed by GABA, whereas the amplitude of the EJPs increased significantly (paired $t$ test, $p<0.05)$, consistent with Figure 1 .

\section{GABA decreases the coefficient of variation of the EJP size}

Repetitive stimulations of the lvn (Fig. 7A) show considerable variation in gm6a EJP amplitude, presumably because of quantal fluctuations in the number of released vesicles. Analysis of trialto-trial fluctuations in EJP amplitude can yield information about the mean quantal content of an EJP and, indirectly, the probability of release. If the probability of vesicle release can be described by Poisson statistics, the coefficient of variation $(\mathrm{CV})$ of the EJP amplitude, defined as the SD divided by the mean, should decrease with increased probability of release.

We calculated the CV for MG-gm6a EJPs in control saline and after $15 \mathrm{~min}$ in $10^{-4} \mathrm{M}$ GABA. We computed the $\mathrm{CV}$ in each condition from the amplitude of 100 EJPs, stimulated at $3 \mathrm{sec}$ 
intervals. In Figure $7 B$ the data from one experiment are binned to show the distribution of amplitudes in both conditions. As expected, the mean amplitude of the EJP increased in GABA. More important, the distribution narrowed; the $\mathrm{CV}$ in control was 0.26 and in GABA was 0.23 . Figure $7 C$ summarizes the results of four such experiments. The decrease was significant (paired $t$ test, $p<0.01$ ).

\section{GABA increases miniature excitatory junctional potential frequency but not amplitude}

We measured miniature excitatory junctional potentials (mEJPs) in the gm6a muscle in control saline, in saline containing $10^{-4} \mathrm{M}$ GABA and $10^{-5} \mathrm{M} \operatorname{PTX}(n=6)$ or $10^{-4} \mathrm{M}$ baclofen $(n=2)$, and in saline containing $10^{-4} \mathrm{M}$ GABA and $10^{-5} \mathrm{M} \operatorname{PTX}(n=5)$ in the presence of TTX $\left(10^{-7}\right.$ to $\left.10^{-6} \mathrm{M}\right)$. Figure $8 A$ shows typical traces of mEJPs recorded intracellularly in gm6a in normal saline. Figure $8 B$ shows the results of a single preparation in which we measured mEJPs for $10 \mathrm{~min}$ stretches of time in control saline (black bars) and in GABA ( gray bars). Note that the number of events increased by $\sim 50 \%$, whereas the distribution of amplitudes remained the same. The inset shows that the nerve-evoked EJP (average of 100 traces) recorded in the same preparation also increased in size in the presence of GABA (Fig. 8B). Both effects washed out after $>30$ min (data not shown).

We studied the effects of GABA on mEJPs in eight preparations in the absence of TTX and in five preparations in the presence of TTX. There were no statistical differences in the amplitude or the frequency of the mEJPs in TTX in either condition compared with those in the absence of TTX. Figure $8 C$ is a histogram plot of the amplitudes of the first 22 mEJPs recorded in each of the 13 experiments. This plot shows that GABA and PTX or baclofen has no significant effect on mEJP amplitude $(0.151 \pm 0.009 \mathrm{mV}$ in normal saline or TTX vs $0.154 \pm$ $0.01 \mathrm{mV}$ in GABA/PTX, baclofen, or GABA/PTX/TTX; paired $t$ test). This was also true if all events recorded across preparations were pooled $(0.254 \pm 0.104 \mathrm{mV}$ in normal saline or TTX vs $0.250 \pm 0.103 \mathrm{mV}$ in GABA/PTX, baclofen, or GABA/PTX/ TTX; paired $t$ test). In contrast, Figure $8 D$ shows that in 12 of the 13 experiments GABA or baclofen significantly increased mEJP frequency $(0.103 \pm 0.014 \mathrm{~Hz}$ in normal saline or TTX vs $0.171 \pm$ $0.026 \mathrm{~Hz}$ in GABA/PTX, baclofen, or GABA/PTX/TTX; $p<$ 0.01 , paired $t$ test).

\section{The effect of GABA is found at both sets of motor neuron terminals on the gm6a muscle and on both muscles innervated by MG}

The gm6a muscle is also innervated by the LG motor neuron. To see whether the LG-gm6a neuromuscular junction was similarly affected by GABA, we stimulated the mvn to evoke LG EJPs. To prevent decreases in muscle fiber resistance that could obscure a change in EJP amplitude, we did the measurements in the presence of $10^{-5} \mathrm{M}$ PTX. The average EJP amplitude $(n=10$ experiments) was $3.10 \pm 0.48 \mathrm{mV}$ in PTX and was $4.60 \pm 0.82$ $\mathrm{mV}$ after $15 \mathrm{~min}$ in $10^{-4} \mathrm{M}$ GABA and PTX. The difference in the amplitude was significant (paired $t$ test, $p<0.01$ ).

The nearby gm 9 muscle is innervated by the MG neuron. In the presence of $10^{-5} \mathrm{M}$ PTX, we stimulated the lvn and measured the resulting EJPs. The average EJP amplitude ( $n=6$ experiments) was $5.51 \pm 1.15 \mathrm{mV}$ in PTX and was $7.45 \pm 1.32 \mathrm{mV}$ after $15 \mathrm{~min}$ in $10^{-4} \mathrm{M}$ GABA and PTX. The difference in the amplitude was significant (paired $t$ test, $p<0.01$ ). Together these experiments show that the excitatory synapses of both the LG and MG motor neurons on both gm 9 and gm6a were enhanced by GABA.

\section{DISCUSSION \\ $\mathrm{GABA}_{\mathrm{B}}$-like receptor increases synaptic efficacy}

The data presented in this paper are all consistent with the interpretation that GABA acts presynaptically via a $\mathrm{GABA}_{\mathrm{B}}$-like receptor to increase the amount of neurotransmitter released by the MG, LG, and LP motor neurons onto the gm6a, gm9, and p1 muscles of the lobster stomach. We found that GABA caused two effects on neuromuscular junctions in the lobster stomach: a rapid postsynaptic conductance increase and a slower enhancement of EJP amplitude. The first effect seems to occur via activation of postsynaptic $\mathrm{GABA}_{\mathrm{A}}$-like channels because it rapidly increased conductance of the muscle fiber, was blocked by picrotoxin (Albert et al., 1986), and was mimicked by muscimol. The second effect is likely caused by activation of $\mathrm{GABA}_{\mathrm{B}}$-like receptors because it occurred more slowly, suggesting a potential metabotropic mechanism, and was mimicked by application of baclofen, but not muscimol. In further support that these two effects occur via separate mechanisms, GABA caused a slow enhancement of the EJP without eliciting a significant postsynaptic effect at the $\mathrm{p} 1$ neuromuscular junction.

Phaclofen and other vertebrate $\mathrm{GABA}_{\mathrm{B}}$ antagonists were ineffective at blocking the GABA-evoked EJP enhancement. However, this is similar to their lack of actions on GABA responses in the crab STG (Swensen et al., 2000) and is consistent with the observation that agonists effective on vertebrate receptors often retain activity in crustacean species, whereas antagonists are often less effective (Marder and Paupardin-Tritsch, 1980). This is understandable, because a single amino acid change can alter the pharmacological profile of Drosophila GABA receptors (Zhang et al., 1994, 1995; Hosie et al., 1997). Additionally, GABA receptors have been reported in vertebrate species that are insensitive to phaclofen (Bonanno et al., 1997) and to CGP 35348 (Bonanno and Raiteri, 1992), suggesting that there may be pharmacologically distinct classes of $\mathrm{GABA}_{\mathrm{B}}$ receptors (Bonanno and Raiteri, 1993).

Three observations support the argument that the slow enhancement of EJPs occurs via a presynaptic mechanism that increases the probability of vesicle release. First, the response to iontophoretically applied glutamate recorded in the muscle fiber was unchanged, but nerve-evoked responses were potentiated by GABA. Second, the coefficient of variation of nerve-evoked EJPs decreased in GABA. Third, the frequency, but not the amplitude, of mEJPs increased in a reversible manner with GABA applications, and this effect persisted in TTX.

\section{Possible mechanisms for GABA enhancement of EJPs}

In many preparations GABA causes an excitatory effect mediated by $\mathrm{GABA}_{\mathrm{A}}$ chloride channels (Alger and Nicoll, 1979; Andersen et al., 1980; Thalmann et al., 1981; Nistri and Sivilotti, 1985; Arakawa and Okada, 1988; Staley and Proctor, 1999). The depolarization probably occurs via changes in the chloride reversal potential and/or efflux of bicarbonate anions via the $\mathrm{GABA}_{\mathrm{A}}$ channels. There is ample precedent for $\mathrm{GABA}_{\mathrm{B}}$-mediated actions on both $\mathrm{Ca}^{2+}$ and $\mathrm{K}^{+}$currents (Dunlap and Fischbach, 1981; Gahwiler and Brown, 1985; Dolphin and Scott, 1987; Saint et al., 1990; Gage, 1992; Mintz and Bean, 1993), although in most cases the net effect of these actions is inhibitory, because GABA decreases $\mathrm{Ca}^{2+}$ currents and/or enhances $\mathrm{K}^{+}$currents. Despite these findings there is no a priori reason why GABA cannot have an excitatory effect. Neurotransmitters are known to act in opposite directions in different target neurons (Licata et al., 1993; 

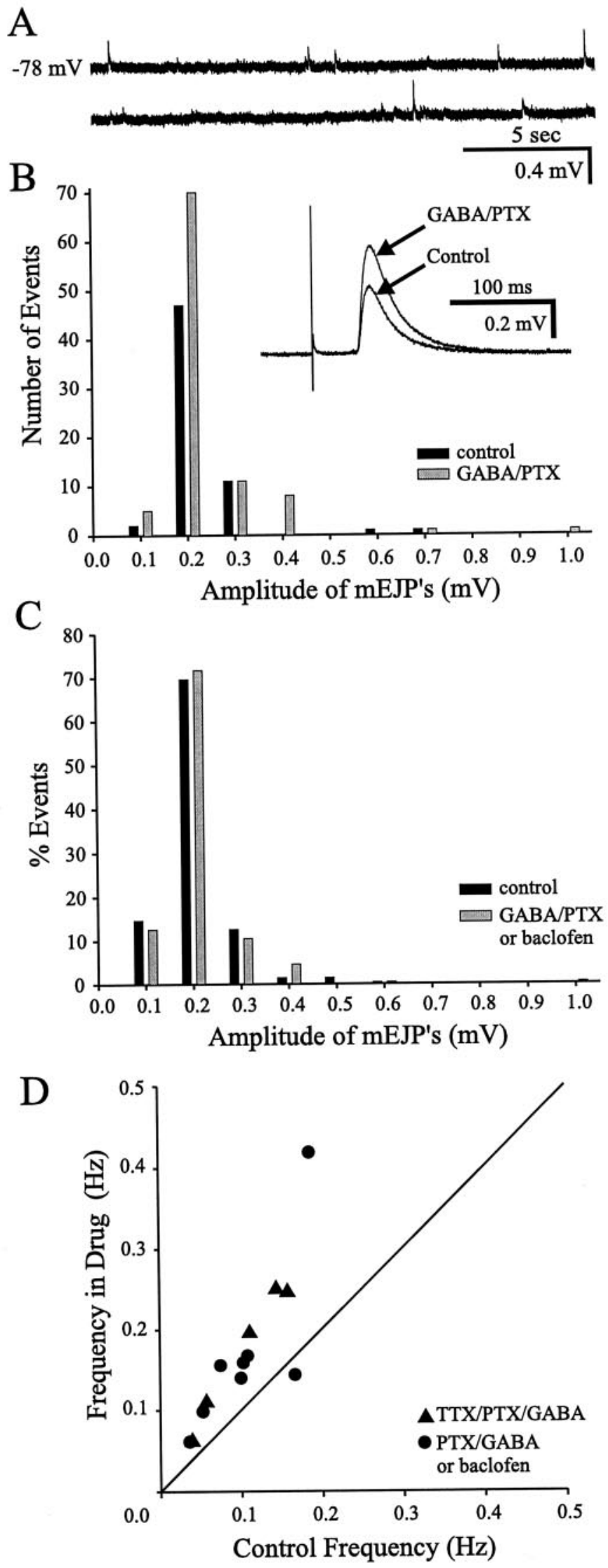

Figure 8. GABA or baclofen increases the frequency but not the amplitude of miniature excitatory junctional potentials in the gm6a muscle. $A$, Typical mEJPs recorded in normal saline in a gm6a muscle fiber are shown

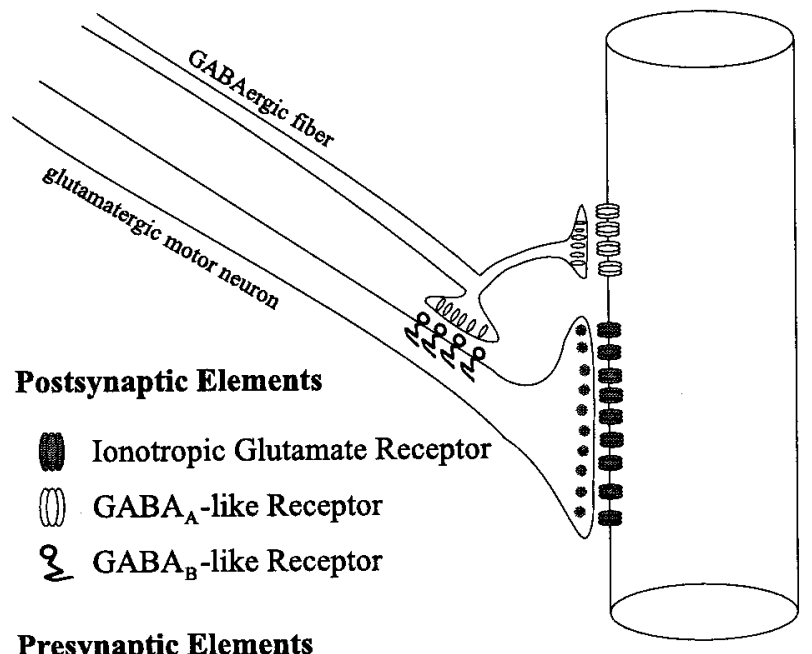

\section{Presynaptic Elements \\ Glutamate Vesicle \\ 0 GABA Vesicle}

gm6a or gm9 muscle fiber

Figure 9. A diagram depicting the possible actions of GABA. A GABAergic axon makes synaptic contact on the muscle fiber (right) and on the glutamatergic motor neuron (left). The glutamate- and GABAcontaining vesicles are shown as filled and open symbols, respectively. $\mathrm{GABA}_{\mathrm{A}}$-like receptors (open symbols) are located in the muscle membrane, and $\mathrm{GABA}_{\mathrm{B}}$-like receptors (squiggles) located presynaptically in the motor neuron terminal enhance transmitter release.

Zhou and Hablitz, 1999) or can elicit multiple responses from the same neuron (Kehoe, 1972).

Figure 9 is a diagram consistent with our physiological data that shows how GABA might influence neuromuscular junctions in the lobster stomach. It shows the presence of pharmacologically different classes of GABA receptors on the muscle and on the excitatory nerve terminal. In this scheme the postjunctional increase in conductance is mediated by activation of $\mathrm{GABA}_{\mathrm{A}}$-like receptors (open symbols) located in the muscle membrane. The increase in the EJP amplitude is mediated by activation of metabotropic $\mathrm{GABA}_{\mathrm{B}}$-like receptors (squiggles) located in the excitatory motor nerve terminal. The increase in the EJP amplitude may occur via modulation of voltage-gated ion channels in the synaptic terminal (i.e., increased $\mathrm{Ca}^{2+}$ conductance or decreased $\mathrm{K}^{+}$conductance), by directly depolarizing (Swensen et al., 2000) the terminal, or via other mechanisms that allow increased transmitter release.

The possible presence of a GABAergic fiber that makes presynaptic connections onto the terminal of the excitatory motor neuron raises the logical possibility that the GABA-evoked en-

in two consecutive intervals. $B$, A histogram plot of mEJPs recorded in a single preparation shows that after a $15 \mathrm{~min}$ application of $10^{-4} \mathrm{M}$ GABA and $10^{-5}$ M PTX ( gray bars), frequency increased compared with control (black bars), whereas the relative distribution of amplitudes remained the same. Inset, The nerve-evoked EJP also increased in the same preparation after drug application. Both effects washed out after $\sim 50 \mathrm{~min}$ (data not shown). $C$, A histogram plot of the amplitude of the first 22 mEJPs recorded in 13 preparations shows that application of GABA and PTX or baclofen (gray bars) had no significant effect on the distribution of mEJP amplitudes. $D$, A plot of mEJP frequency in control saline versus mEJP frequency in drug shows that in 12 of 13 preparations GABA and PTX or baclofen increased frequency in the absence (circles) or presence (triangles) of TTX. A reference line with a slope of 1 is plotted (solid line). 
hancement of EJP amplitude could occur if the GABAergic fiber had conventional inhibitory autoreceptors, and if GABA were being continuously released. In this model, the enhancement could occur as disinhibition; the application of exogenous GABA results in a decrease in the release of GABA onto the presynaptic glutamatergic fiber. In this case, the cellular actions of GABA could be quite conventional, but the net effect would be excitatory. We believe that this interpretation is unlikely because it is not consistent with the effects of GABA on mEJP frequency, especially those seen in the presence of TTX. TTX would suppress all action potential-evoked release of GABA from any presynaptic fiber. In the presence of TTX, the effects on the mEJPs should be uninfluenced by the presence of the GABAergic fiber, and therefore the effects on mEJP frequency must be caused by the direct actions of GABA on the excitatory terminal. Therefore, the increased frequency of mEJPs seen in GABA would argue that GABA is acting directly to enhance transmitter release from the presynaptic terminal.

There are other reports that suggest that GABA may enhance synaptic release by activating depolarizing $\mathrm{GABA}_{\mathrm{A}}$ receptors or via network interactions (Nistri and Sivilotti, 1985; Arakawa and Okada, 1988). Brenowitz et al. (1998) showed that GABA activation of presynaptic $\mathrm{GABA}_{\mathrm{B}}$ receptors decreases the amount of synaptic depression at auditory glutamatergic synapses. Because of this, the EPSCs evoked by high-frequency trains of stimuli are larger in baclofen than in the control. The authors argue that this occurs precisely because baclofen decreases transmitter release early in the train, and therefore there is more residual transmitter available for release by subsequent pulses (Brenowitz et al., 1998). Alternatively, it is possible that those terminals might also express a second $\mathrm{GABA}_{\mathrm{B}}$ action analogous to the one we report here, by which GABA directly enhances transmitter release.

\section{Anatomical evidence consistent with the presynaptic peripheral role of GABA}

A relatively high concentration of bath-applied GABA $\left(>10^{-5} \mathrm{M}\right)$ is required for either the muscle fiber input resistance decrease or the increase in EJP amplitude (Fig. 1D). What might be the source of the GABA? Studies of the distribution of GABA immunoreactivity in a variety of crustacean species, including lobsters, show that none of the STG motor neuron somata stain for GABA (Cournil et al., 1990; Mulloney and Hall, 1990; Swensen et al., 2000). However, GABA is found in inputs to the stomatogastric ganglion (Cournil et al., 1990; Blitz and Nusbaum, 1999), some of which project through the STG into the motor nerves (Swensen et al., 2000), and may be responsible for recent observations of inhibitory synapses onto stomach muscles (Sharman et al., 2000). Particularly relevant for this work, Sharman et al. (2000) found ultrastructural evidence of inhibitory synapses onto the axons of excitatory motor neurons in crabs.

\section{Possible physiological significance of the opposing effects of GABA}

The opposing presynaptic enhancement and postsynaptic inhibition evoked by GABA appear at first to be paradoxical. Nonetheless, similar phenomena have been described in other neuromuscular systems. In Aplysia a motor neuron innervating the radula closer muscle coreleases neuromodulatory substances that have opposing effects: a presynaptically mediated decrease in neurotransmitter release and a postsynaptically mediated increase in muscle contraction strength and relaxation time (Vilim et al., 1996a,b). When feeding, Aplysia move food into the mouth by rhythmic opening and closing of the radula. It is hypothesized that as the animal eats more quickly, or with stronger force of contraction, the closer muscle will not completely relax before the opener muscle contracts, and functional feeding cannot occur. Neuromodulatory substances are preferentially released from the motor neuron during higher frequency firing and cause the radula closer muscle to contract less forcefully and relax more quickly and may allow the radula to open and close at a faster rate (Vilim et al., 1996a,b, 2000). Similarly, in the locust, release of octopamine at some wing and leg muscle neuromuscular junctions increases the muscle relaxation rate, allowing the muscles to respond to more rapid input during flight corrections or walking (Evans and Siegler, 1982; Stevenson and Meuser, 1997; Baudoux et al., 1998).

A similar situation may be occurring in the lobster stomach muscles. Release of GABA at the neuromuscular junction may decrease EJP duration and increase the muscle relaxation rate by increasing postsynaptic conductance. Also, GABA may increase EJP amplitude and contraction strength by enhancing transmitter release. In principle, these two effects may allow stomach muscles to follow faster rhythmic input by increasing the muscle relaxation rate, while maintaining a similar peak contraction strength. The presence of a GABAergic neuromodulatory network in the lobster could allow rhythmic stomatogastric muscle contraction, and therefore feeding behavior, over a wider range of frequencies and strengths than otherwise possible. This may represent a mechanism by which the animal adapts to variability in its natural environment.

\section{REFERENCES}

Albert J, Lingle CJ, Marder E, O’Neil MB (1986) A GABA-activated chloride-conductance not blocked by picrotoxin on spiny lobster neuromuscular preparations. Br J Pharmacol 87:771-779.

Alger BE, Nicoll RA (1979) GABA-mediated biphasic inhibitory responses in hippocampus. Nature 281:315-317.

Andersen P, Dingledine R, Gjerstad L, Langmoen IA, Laursen AM (1980) Two different responses of hippocampal pyramidal cells to application of gamma-aminobutyric acid. J Physiol (Lond) 305:279-296.

Arakawa T, Okada Y (1988) Excitatory and inhibitory action of GABA on synaptic transmission in slices of guinea pig superior colliculus. Eur J Pharmacol 158:217-224.

Baudoux S, Duch C, Morris OT (1998) Coupling of efferent neuromodulatory neurons to rhythmical leg motor activity in the locust. J Neurophysiol 79:361-370.

Beaumont V, Zucker RS (2000) Enhancement of synaptic transmission by cyclic AMP modulation of presynaptic $I_{h}$ channels. Nat Neurosci 3:133-141.

Blitz DM, Nusbaum MP (1999) Distinct functions for cotransmitters mediating motor pattern selection. J Neurosci 19:6774-6783.

Bonanno G, Raiteri M (1992) Functional evidence for multiple gammaaminobutyric acid $_{\mathrm{B}}$ receptor subtypes in the rat cerebral cortex. J Pharmacol Exp Ther 262:114-118.

Bonanno G, Raiteri M (1993) Multiple $\mathrm{GABA}_{\mathrm{B}}$ receptors. Trends Pharmacol Sci 14:259-261.

Bonanno G, Fassio A, Schmid G, Severi P, Sala R, Raiteri M (1997) Pharmacologically distinct $\mathrm{GABA}_{\mathrm{B}}$ receptors that mediate inhibition of GABA and glutamate release in human neocortex. Br J Pharmacol 120:60-64.

Brenowitz S, David J, Trussell L (1998) Enhancement of synaptic efficacy by presynaptic $\mathrm{GABA}_{\mathrm{B}}$ receptors. Neuron 20:135-141.

Cournil I, Meyrand P, Moulins M (1990) Identification of all GABAimmunoreactive neurons projecting to the lobster stomatogastric ganglion. J Neurocytol 19:478-493.

Delaney K, Tank DW, Zucker RS (1991) Presynaptic calcium and serotonin-mediated enhancement of transmitter release at crayfish neuromuscular junction. J Neurosci 11:2631-2643.

Dolphin AC, Scott RH (1987) Calcium channel currents and their inhibition by $(-)$-baclofen in rat sensory neurones: modulation by guanine nucleotides. J Physiol (Lond) 386:1-17.

Dudel J, Kuffler SW (1961) Presynaptic inhibition at the crayfish neuromuscular junction. J Physiol (Lond)155:543-562.

Dunlap K, Fischbach GD (1981) Neurotransmitters decrease the cal- 
cium conductance activated by depolarization of embryonic chick sensory neurones. J Physiol (Lond) 317:519-535.

Eliot LS, Kandel ER, Siegelbaum SA, Blumenfeld H (1993) Imaging terminals of Aplysia sensory neurons demonstrate role of enhanced $\mathrm{Ca}^{2+}$ influx in presynaptic facilitation. Nature 361:634-637.

el Manira A, Clarac F (1994) Presynaptic inhibition is mediated by histamine and GABA in the crustacean escape reaction. J Neurophysiol 71:1088-1095.

Evans PD, Siegler MVS (1982) Octopamine mediated relaxation of maintained and catch tension in locust skeletal muscle. J Physiol (Lond) 324:93-112.

Fischer Y, Parnas I (1996) Activation of $\mathrm{GABA}_{\mathrm{B}}$ receptors at individual release boutons of the crayfish opener neuromuscular junction produces presynaptic inhibition. J Neurophysiol 75:1377-1385.

Fuchs PA, Getting PA (1980) Ionic basis of presynaptic inhibitory potentials at crayfish claw opener. J Neurophysiol 43:1547-1557.

Gage PW (1992) Activation and modulation of neuronal $\mathrm{K}^{+}$channels by GABA. Trends Neurosci 15:46-51.

Gahwiler BH, Brown DA (1985) GABA $_{\mathrm{B}}$-receptor-activated K ${ }^{+}$current in voltage-clamped CA3 pyramidal cells in hippocampal cultures. Proc Natl Acad Sci USA 82:1558-1562.

Hawkins RD, Kandel ER, Siegelbaum SA (1993) Learning to modulate transmitter release: themes and variations in synaptic plasticity. Annu Rev Neurosci 16:625-665.

Holz GG, Kream RM, Spiegel A, Dunlap K (1989) G proteins couple alpha-adrenergic and $\mathrm{GABA}_{\mathrm{b}}$ receptors to inhibition of peptide secretion from peripheral sensory neurons. J Neurosci 9:657-666.

Hosie AM, Aronstein K, Sattelle DB, ffrench-Constant RH (1997) Molecular biology of insect neuronal GABA receptors. Trends Neurosci 20:578-583.

Isaacson JS, Hille B (1997) $\mathrm{GABA}_{\mathrm{B}}$-mediated presynaptic inhibition of excitatory transmission and synaptic vesicle dynamics in cultured hippocampal neurons. Neuron 18:143-152.

Kehoe J (1972) The physiological role of three acetylcholine receptors in synaptic transmission in Aplysia. J Physiol (Lond) 225:147-172.

Kerr DI, Ong J, Prager RH, Gynther BD, Curtis DR (1987) Phaclofen: a peripheral and central baclofen antagonist. Brain Res 405:150-154.

Lanza M, Fassio A, Gemignani A, Bonanno G, Raiteri M (1993) CGP 52432: a novel potent and selective $\mathrm{GABA}_{\mathrm{B}}$ autoreceptor antagonist in rat cerebral cortex. Eur J Pharmacol 237:191-195.

Licata F, Volsi GL, Maugeri G, Santangelo F (1993) Excitatory and inhibitory effects of 5-hydroxytryptamine on the firing rate of medial vestibular nucleus neurons in the rat. Neurosci Lett 154:195-198.

Lim R, Alvarez FJ, Walmsley B (2000) GABA mediates presynaptic inhibition at glycinergic synapses in a rat auditory brainstem nucleus. J Physiol (Lond) 525:447-459.

Lingle C (1980) The sensitivity of decapod foregut muscles to acetylcholine and glutamate. J Comp Physiol [A] 138:187-199.

MacDermott AB, Role LW, Siegelbaum SA (1999) Presynaptic ionotropic receptors and the control of transmitter release. Annu Rev Neurosci 22:443-485.

Marder E, Paupardin-Tritsch D (1980) The pharmacological profile of the acetylcholine response of a crustacean muscle. $J$ Exp Biol 88:147-159.

Matthews G, Ayoub GS, Heidelberger R (1994) Presynaptic inhibition by GABA is mediated via two distinct GABA receptors with novel pharmacology. J Neurosci 14:1079-1090.

Maynard DM, Dando MR (1974) The structure of the stomatogastric neuromuscular system in Callinectes sapidus, Homarus americanus and Panulirus argus (Decapoda crustacea). Philos Trans R Soc Lond B Biol Sci 268:161-220.

Mintz IM, Bean BP (1993) GABA $_{B}$ receptor inhibition of P-type $\mathrm{Ca}^{2+}$ channels in central neurons. Neuron 10:889-898.
Miwa A, Ui M, Kawai N (1990) G protein is coupled to presynaptic glutamate and GABA receptors in lobster neuromuscular synapse. J Neurophysiol 63:173-180.

Mulloney B, Hall WM (1990) GABA-ergic neurons in the crayfish nervous system: an immunocytochemical census of the segmental ganglia and stomatogastric system. J Comp Neurol 291:383-394.

Nistri A, Sivilotti L (1985) An unusual effect of gamma-aminobutyric acid on synaptic transmission of frog tectal neurones in vitro. Br J Pharmacol 85:917-921.

Olpe HR, Karlsson G, Pozza MF, Brugger F, Steinmann M, Van Riezen H, Fagg G, Hall RG, Froestl W, Bittiger H (1990) CGP 35348: a centrally active blocker of $\mathrm{GABA}_{\mathrm{B}}$ receptors. Eur $\mathrm{J}$ Pharmacol 187:27-38.

Olpe HR, Steinmann MW, Ferrat T, Pozza MF, Greiner K, Brugger F, Froestl W, Mickel SJ, Bittiger H (1993) The actions of orally active $\mathrm{GABA}_{\mathrm{B}}$ receptor antagonists on GABAergic transmission in vivo and in vitro. Eur J Pharmacol 233:179-186.

Rathmayer W, Djokaj S (2000) Presynaptic inhibition and the participation of $\mathrm{GABA}_{\mathrm{B}}$ receptors at neuromuscular junctions of the crab Eriphia spinifrons. J Comp Physiol [A] 186:287-298.

Richards KS, Miller WL, Marder E (1999) Maturation of the rhythmic activity produced by the stomatogastric ganglion of the lobster, Homarus americanus. J Neurophysiol 82:2006-2009.

Saint DA, Thomas T, Gage PW (1990) GABA G $_{\mathrm{B}}$ agonists modulate a transient potassium current in cultured mammalian hippocampal neurons. Neurosci Lett 118:9-13.

Sharman A, Hirji R, Birmingham JT, Govind CK (2000) Crab stomach pyloric muscles display not only excitatory but inhibitory and neuromodulatory nerve terminals. J Comp Neurol 425:70-81.

Staley KJ, Proctor WR (1999) Modulation of mammalian dendritic $\mathrm{GABA}(\mathrm{A})$ receptor function by the kinetics of $\mathrm{Cl}-$ and $\mathrm{HCO} 3-$ transport. J Physiol (Lond) 519:693-712.

Stevenson P, Meuser S (1997) Octopaminergic innervation and modulation of a locust flight steering muscle. J Exp Biol 200:633-642.

Swensen AM, Golowasch J, Christie AE, Coleman MJ, Nusbaum MP, Marder E (2000) GABA and responses to GABA in the stomatogastric ganglion of the crab Cancer borealis. J Exp Biol 203:2075-2092.

Thalmann RH, Peck EJ, Ayala GF (1981) Biphasic response of hippocampal pyramidal neurons to GABA. Neurosci Lett 21:319-324.

Vilim FS, Price DA, Lesser W, Kupfermann I, Weiss KR (1996a) Costorage and corelease of modulatory peptide cotransmitters with partially antagonistic actions on the accessory radula closer muscle of Aplysia californica. J Neurosci 16:8092-8104.

Vilim FS, Cropper EC, Price DA, Kupfermann I, Weiss KR (1996b) Release of peptide cotransmitters in Aplysia: regulation and functional implications. J Neurosci 16:8105-8114.

Vilim FS, Cropper EC, Price DA, Kupfermann I, Weiss KR (2000) Peptide cotransmitter release from motor neuron B16 in Aplysia californica: costorage, corelease, and functional implications. J Neurosci 20:2036-2042.

Wu LG, Saggau P (1997) Presynaptic inhibition of elicited neurotransmitter release. Trends Neurosci 20:204-212.

Zhang HG, ffrench-Constant RH, Jackson MB (1994) A unique amino acid of the Drosophila GABA receptor with influence on drug sensitivity by two mechanisms. J Physiol (Lond) 479:65-75.

Zhang HG, Lee HJ, Rocheleau T, ffrench-Constant RH, Jackson MB (1995) Subunit composition determines picrotoxin and bicuculline sensitivity of Drosophila gamma-aminobutyric acid receptors. Mol Pharmacol 48:835-840.

Zhou FM, Hablitz JJ (1999) Dopamine modulation of membrane and synaptic properties of interneurons in rat cerebral cortex. J Neurophysiol 81:967-976. 